\title{
International recognition of the links between transport, health and sustainability
}

Dr Jennifer S Mindell, Editor-in-chief

Sustainability is intimately tied to the transport-health relationship and is an inherent part of the work reported in this journal. The synergies between sustainable - also called 'green' or 'low carbon' - transport policies and health-promoting transport policies are well-recognised (Mindell et al, 2011). Reductions in travel by aeroplane or private car, more walking and cycling, public transport (transit) use for journeys that cannot be travelled on foot or bicycle, together with reductions in trips and particularly in distances will all yield a wide range of benefits for individuals, local communities, wider society and the planet.

Transport and health is increasingly being acknowledged internationally as an important area that affects the population's quality of life, relationships with the built and natural environment, social justice and inequalities, as well as societal costs, both in economic terms and relating to sustainability, including some of the UN Sustainability Development Goals (SDGs). Achieving a shift towards more sustainable modes requires changes beyond transport planning and public health policy, particularly a shift in spatial planning to put education, work, and social activities within short distances of home. This needs political will. It is good news that in June 2017, the Transport Ministers of the 57 member countries of the International Transport Federation (ITF) issued a statement on transport, in which they articulated their political will to improve governance to achieve internationally agreed objectives. These include those set by the Paris Climate Agreement and the SDGs. They confirmed the importance of co-operation as urbanisation increases worldwide, to ensure that urban transport systems provide inclusive access to services in a sustainable way, with improved co-ordination of transport, land use, and fiscal policies (International Transport Federation, 2017) The challenge for researchers is to produce evidence-relevant research (GilesCorti et al, 2015). It is therefore timely that Khreis and colleagues (2017) have summarised a large range of urban transport policies to help practitioners understand the potential health impacts. Boehmer et al (2017) have done similar work in the USA, producing a Transport and Health Tool for USA practitioners.

Modelling tools help to quantify the important connections between transport and health as well as other outcomes. Maizlish and colleagues (2017) have used the Integrated Transport and Health Impact Modeling tool (ITHIM (Whitfield et al, 2017; based on Woodcock et al, 2009)) to demonstrate how increasing walking and cycling for transport can not only improve the health of those individuals but can also contribute to slowing the forecast rise in $\mathrm{CO}_{2}$ emissions in California. Use of the Health Economic Assessment Tool (HEAT) demonstrated that the number of deaths averted by increased active travel in the Netherlands varies by population sub-group, being larger in those groups that walk or cycle more (older people, the wealthier, and Dutch-born residents) but also among poorer groups that have a higher burden of disease (Gao, 2017). The authors point out that encouraging more active travel among the population groups with lower walking and cycling levels could not only improve population-level health but may also reduce inequalities.

Empirical studies provide more evidence of the connections between transport, health, and sustainability. In Sydney, Australia, cycling increased among people living near a new cycleway, particularly those living 1-3km from the new infrastructure, at a time of reduced cycling elsewhere. Social capital also increased in that area, although overall physical activity and quality of life did not (Crane et al, 2017). A study comparing energy expenditure and $\mathrm{VO}_{2}$ (oxygen consumption) when travelling a hilly $4.4 \mathrm{~km}$ route on foot, by bicycle, or e-bike found that energy expenditure and $\mathrm{VO}_{2}$ 
per minute were the same for all three modes, but because of the decreased duration of travel across the three modes, e-bikes expended $24 \%$ less energy than conventional bikes and $64 \%$ less than walking (Langford et al, 2017).

In this issue, Kwan et al (2017) also combine these themes of sustainability, reducing $\mathrm{CO}_{2}$ emissions, air pollution and public transport. They conclude that although two mass rapid transit lines in Greater Kuala Lumpur, Malaysia, would reduce $\mathrm{CO}_{2}$ emissions substantially, use of private motor vehicles to travel to or from the stations would reduce the benefits by a quarter. Huang et al (2017) found an increase in station-related walking among people living within 1 mile after the opening of new light rail transit stations in Seattle, but overall walking fell. They posit that walking will increase over time, as transit-oriented development increases, bringing both more businesses and more people living within walking distance (ideally $<0.75$ mile) of the station and these other potential destinations. These benefits that mass rapid transit (bus rapid transit (BRT) and light rail) can bring are exemplified by the recent Transport Achievement Award given by the International Transport Federation (https://www.itf-oecd.org/) to the Metrobus 9 de Julio project in Buenos Aires, Argentina, which led to fewer cars, reduced $\mathrm{CO}_{2}$ emissions from traffic, more pedestrians, and new businesses opening.

Shorter distances, higher residential densities, and more potential destinations were among the elements associated with walkability and more walking in an Australian context (Badland et al, 2017). This research group have now examined factors associated with a number of different travel modes in residents of Melbourne, Australia. They found similar associations between walking, cycling or public transport trips with high intersection density, residential density, land use mix, diversity of destinations and proximity of key destinations including supermarkets and public stations; the same factors were associated with reduced car use (Boulange et al, 2017).

Congratulations to the organisers of the third International Conference on Transport and Health (ICTH), held in June 2017 at ISGlobal, Barcelona, and to the winners of the various prizes for high scoring abstracts and posters. As with the preceding two conferences, the accepted abstracts were published by this journal and are available in an open access, online supplement to volume 5 , at www.sciencedirect.com/science/journal/22141405/5/supp/S?sdc=1. Any published papers that are based on work presented at ICTH will also be available through our system of Virtual Special Issues, at www.sciencedirect.com/science/journal/22141405/vsi/10B1N46737R?sdc=1. Next year's conference will be in Michigan 24-27 June 2018 (www.tphlink.com/conference-schedule.html).

\section{References}

Badland H, Suzanne Mavoa, Claire Boulangé, Serryn Eagleson, Lucy Gunn, Joshua Stewart, Stephanie David, Billie Giles-Corti (2017), Identifying, creating, and testing urban planning measures for transport walking: Findings from the Australian national liveability study. J Transp Health. Vol 5 151162 http://dx.doi.org/10.1016/i.jth.2016.08.010.

Boehmer T, Arthur Wendel , Frederick Bowers, Katherine Robb, Ed Christopher, Jason Broehm , Ken Rose, Joseph Ralph (2017). U.S. Transportation and Health Tool: Data for Action. J Transp Health. Vol 6, PAGE NUMBERS TO BE ADDED BY THE ELSEVIER TEAM.

Boulange C, Lucy Gunn, Billie Giles-Corti, Suzanne Mavoa, Hannah Badland, Chris Pettit. Examining associations between urban design attributes and transport mode choice for walking, cycling, public transport and private motor vehicle trips. J Transp Health. Vol 6, PAGE NUMBERS TO BE ADDED BY THE ELSEVIER TEAM.

Chieng M, Hakkan Lai, Alistair Woodward (2017) How dangerous is cycling in New Zealand? J Transp Health. Vol 6, PAGE NUMBERS TO BE ADDED BY THE ELSEVIER TEAM.

http://dx.doi.org/10.1016/j.jth.2017.02.008. 
Crane M, Chris Rissel, Christopher Standen, Adrian Ellison, Richard Ellison, Li Ming Wen, Stephen Greaves (2017) Longitudinal evaluation of travel and health outcomes in relation to new bicycle infrastructure, Sydney, Australia. J Transp Health. Vol 6, PAGE NUMBERS TO BE ADDED BY THE ELSEVIER TEAM.

Gao J, Marco Helbich, Martin Dijst, Carlijn B.M. Kamphuis, Socioeconomic and demographic differences in walking and cycling in the Netherlands: How do these translate into differences in health benefits? J Transp Health. Vol 6, PAGE NUMBERS TO BE ADDED BY THE ELSEVIER TEAM. http://dx.doi.org/10.1016/j.jth.2017.06.001.

Giles-Corti B, Sallis JF, Sugiyama T, Frank LD, Lowe M, Owen N. (2015) Translating active living research into policy and practice: One important pathway to chronic disease prevention. Journal of Public Health Policy 36, 231-243. doi:10.1057/jphp.2014.53.

Huang R, Anne V. Moudon, Chuan Zhou, Orion T. Stewart, Brian E. Saelens (2017) Light rail leads to more walking around station areas. J Transp Health. Vol 6, PAGE NUMBERS TO BE ADDED BY THE ELSEVIER TEAM. http://dx.doi.org/10.1016/j.jth.2017.02.002.

International Transport Federation (2017). 2017 Ministerial Declaration of Governance of Transport. ITF/OECD, Paris, France . https://www.itf-oecd.org/sites/default/files/docs/2017-ministerialdeclaration-governance-transport.pdf

Khreis H, Anthony D. May, Mark J. Nieuwenhuijsen (2017), Health impacts of urban transport policy measures: A guidance note for practice. J Transp Health. Vol 6, PAGE NUMBERS TO BE ADDED BY THE ELSEVIER TEAM. http://dx.doi.org/10.1016/j.jth.2017.06.003

Kwan SC, Marko Tainio, James Woodcock, Rosnah Sutan, Jamal Hisham Hashim (2017) The carbon savings and health co-benefits from the introduction of mass rapid transit system in Greater Kuala Lumpur, Malaysia. J Transp Health. Vol 6, PAGE NUMBERS TO BE ADDED BY THE ELSEVIER TEAM. http://dx.doi.org/10.1016/i.jth.2017.06.006.

Langford BC, Christopher R. Cherry, David R. Bassett, Eugene C. Fitzhugh, Nirbesh Dhakal (2017) Comparing physical activity of pedal-assist electric bikes with walking and conventional bicycles. J Transp Health. Vol 6, PAGE NUMBERS TO BE ADDED BY THE ELSEVIER TEAM. http://dx.doi.org/10.1016/j.jth.2017.06.002.

Maizlish N, Nicholas J. Linesch, James Woodcock, Health and greenhouse gas mitigation benefits of ambitious expansion of cycling, walking, and transit in California. J Transp Health. Vol 6, PAGE NUMBERS TO BE ADDED BY THE ELSEVIER TEAM. http://dx.doi.org/10.1016/j.jth.2017.04.011.

Mandic S, Charlotte Flaherty, Tessa Pocock, Chiew Ching Kek, Palma Chillón, Christina Ergler, Enrique García Bengoechea, (2017) Parental perceptions of cycle skills training for adolescents. J Transp Health. Vol 6, PAGE NUMBERS TO BE ADDED BY THE ELSEVIER TEAM. http://dx.doi.org/10.1016/j.jth.2017.03.009.

Mindell JS, Cohen JM, Watkins S, Tyler N. (2011) Synergies between low carbon and healthy transport policies. Proceedings of the Institution of Civil Engineers - Transport.164:127-39.

Whitfield GP, Meehan LA, Maizlish N, Wendel AM (2017) The integrated transport and health impact modeling tool in Nashville, Tennessee, USA: Implementation steps and lessons learned. J Transp Health. Vol 5 pp 172-181. http://dx.doi.org.libproxy.ucl.ac.uk/10.1016/j.jth.2016.06.009

Woodcock J, Edwards P, Tonne C, Armstrong BG, Ashiru O, Banister D, et al. (2009) Public health benefits of strategies to reduce greenhouse-gas emissions: urban land transport. Lancet, 374 (9705) pp 1930-1943. 